\title{
Health-related quality of life in COPD: why both disease-specific and generic measures should be used
}

\author{
C.P. Engström*, L.O. Persson\#, S. Larsson*, M. Sullivan
}

Health-related quality of life in COPD: why both disease-specific and generic measures should be used. C.P. Engström, L.O. Persson, S. Larsson, M. Sullivan. (C)ERS Journals Ltd 2001.

ABSTRACT: Although research has consistently demonstrated that chronic obstructive pulmonary disease (COPD) impairs health-related quality of life (HRQL), little agreement has been evidenced regarding the factors identified as contributing to impaired HRQL. The aim was to study such factors using well established generic and specific HRQL instruments.

The patients $(n=68)$ were stratified by forced expiratory volume in one second (FEV1) to represent a wide range of disease severity. Pulmonary function, blood gases and 6-min walking distance test (6MWD) were assessed. HRQL instruments included: St George's Respiratory Questionnaire (SGRQ), Sickness Impact Profile (SIP), Hospital Anxiety and Depression Scale and Mood Adjective Check List.

The strength of the impact of COPD on HRQL was represented along a continuum ranging from lung function, functional status (physical and psychosocial) to wellbeing. Although correlations between FEV1 versus SGRQ total and SIP overall scores $(r=-0.42$ and $\mathbf{- 0 . 3 2})$ were stronger than previously reported, multiple regression analyses showed that lung function contributed little to the variance when dyspnoearelated limitation, depression scores and 6MWD were included in the models. These three factors were important to varying degrees along the whole range of HRQL.

Physiological, functional and psychosocial consequences of chronic obstructive pulmonary disease are only poorly to moderately related to each other. The present study concludes that a comprehensive assessment of the effects of chronic obstructive pulmonary disease requires a battery of instruments that not only tap the diseasespecific effects, but also the overall burden of the disease on everyday functioning and emotional wellbeing.

Eur Respir J 2001; 18: 69-76.
*Dept of Pulmonary Medicine, Sahlgrenska University Hospital, "Dept of Nursing, University of Göteborg, and Health Care Research Unit, Dept of Internal Medicine, Sahlgrenska University Hospital, Göteborg, Sweden.

Correspondence: C.P. Engström, Dept of Pulmonary Medicine, Sahlgrenska University Hospital, SE-413 45 Göteborg, Sweden.

Fax: 4631824904

Keywords: Chronic obstructive pulmonary disease

Hospital Anxiety and Depression Scale mood

quality of life

Sickness Impact Profile

St George's Respiratory Questionnaire

Received: May 162000

Accepted after revision February 20 2001

This study was supported by a grant from The Swedish Council for Social Research.
In chronic obstructive pulmonary disease (COPD), measures of health-related quality of life (HRQL) are nowadays frequently used as descriptive instruments or as outcome measures $[1-6]$. Since cure is still impossible for most COPD patients, a major goal of care is to improve HRQL. However, limited attempts have been made to identify the factors that are related to the different aspects of HRQL in COPD [7]. Such analyses may also shed light on the properties of the questionnaires that are studied and also show their internal relations.

In the case of generic HRQL measures, mainly the Sickness Impact Profile (SIP) [8], three important determinants have been found: exercise tolerance $[1-3]$, symptoms [3, 4, 9, 10] and emotional status $[2,3,10]$. Education [2] and social support [10] have also been shown to explain some of the variance in self-reported health status. All the studies $[1-4,9,10]$ report little or no correlation between the SIP and spirometry, possibly due to a limited range of ventilatory restriction in the populations studied.

Concerning the disease-specific St George's Respiratory Questionnaire (SGRQ) [11], exercise tolerance
[11 - 13], dyspnoea $[11,13,14]$, anxiety $[11,13]$, wheezing [11], body composition [14], fatigue [15] and coping strategies [12] have all been reported as significantly related. The correlation to forced expiratory volume in one second (FEV1) is somewhat stronger than to the SIP [11-14]. Moreover, oxygen tension in arterial blood $\left(\mathrm{Pa}_{\mathrm{a}} \mathrm{O}_{2}\right)$ has been found to be significantly related to total SGRQ in patients with hypoxaemia [16]

Emotional wellbeing has been examined in two studies. In one [17], it was reported to be significantly related to symptoms, especially fatigue, and in the other to coping pattern [12].

Thus, several factors have been reported to relate to HRQL in COPD, but they have not been systematically investigated. The aim of the present work is to identify the factors most highly related to HRQL in a well-defined COPD population, stratified to represent a wide range of disease severity. The variables that were analysed were selected to cover an expected continuum from physiology, diseasespecific problems, functional (generic) and emotional (generic). 


\section{Patients and methods}

\section{Design}

A cross-sectional sample of patients with COPD was recruited, stratified in relation to severity of disease, and examined extensively by physiological tests and a battery of specific and generic HRQL measures. A follow-up was performed after 12 months.

\section{Patients}

Every tenth patient at the outpatient clinic of the Dept of Pulmonary Medicine, Göteborg, Sweden who met inclusion criteria were invited to participate. Inclusion criteria were COPD with FEV $1<80 \%$ predicted and age $40-75$ yrs. All of the patients were smokers or former smokers with a smoking history of $\geqslant 10$ pack-yrs. Exclusion criteria were other disabling or severe diseases and/or coexistence of other causes of impaired pulmonary function. Patients with a history indicating asthma were excluded. None of them were in acute exacerbation at the time of investigation. Patients included were stratified into three groups according to FEV1: $<30 \%, 30-50 \%$, and $50-80 \%$ pred. When a sufficient number of patients were included in one of the three FEV1 categories, no more subjects were added in that category. In total, 68 patients were entered in the study. Clinical and demographic data are given in table 1.

\section{Physiological measurements}

Routine spirometry was assessed with a Vitalograph spirometer (Selefa, Buckingham, Ireland) before and $15 \mathrm{~min}$ after inhalation of $1 \mathrm{mg}$ terbutaline to reach optimal standardization. Carbon monoxide transfer factor was measured with the single-breath method. Values for prediction were those described by
Berglund et al. [18] and SAlorinne [19], respectively. Arterial blood gases $\left(\mathrm{Pa}_{\mathrm{a}} \mathrm{O}_{2}\right.$ and carbon dioxide tension in arterial blood $\left(\mathrm{Pa}, \mathrm{CO}_{2}\right)$ were measured in all patients with a known prebronchodilator $\mathrm{FEV} 1<50 \%$ pred (FEV1 is reported postbronchodilation). Blood gas measurement was performed in 55 patients. All the physiological tests were performed at the same occasion. Finally, a 6-min walking distance test (6MWD) was performed with standardized instructions [20].

\section{Health-related quality of life questionnaires}

Disease specific. St George's Respiratory Questionnaire. This questionnaire comprises 76 items divided into three sections: symptoms (problems caused by specific respiratory symptoms), activity (restriction of activity by dyspnoea) and impacts (impact on everyday life caused by the disease) [11]. Every item has a predetermined weight. Component scores were calculated for each of the three sections and a total score including all items was derived. The scores ranged from $0-100 \%$ of possible distress. A recently validated Swedish version of the SGRQ was used [21].

Generic. Sickness Impact Profile. Functional status was measured by an extensively validated Swedish version [22] of the SIP [8]. This is a well-known generic health status questionnaire, constructed to facilitate comparisons between different health conditions over a range of important functional aspects. It consists of 136 weighted items, grouped into 12 categories: ambulation (A), body care and movement (BCM), mobility (M), emotional behaviour (EB), social interaction (SI), alertness behaviour (AB), communication (C), work (W), sleep and rest (SR), eating (E), home management (HM) and recreation and pastimes (RP). The scale scores are expressed as a percentage of maximum dysfunction to produce a $0-100$ scale. A score of 0 indicates no dysfunction, a score of $>0 \leqslant 10$ indicates slight to moderate dysfunction and a score of $>10$ indicates

Table 1. - Baseline characteristics of the total sample and subgroups according to forced expiratory volume in one second (FEV1) \% predicted

\begin{tabular}{lcccc}
\hline & \multicolumn{3}{c}{ FEV1 \% pred } & Total sample \\
\cline { 2 - 4 } & $79-50$ & $49-30$ & pred $<30$ & \\
\hline Patients n & 22 & 25 & 21 & 68 \\
M:F & $15: 7$ & $16: 9$ & $12: 9$ & $43: 25$ \\
Age yrs & $64.1 \pm 6.4$ & $64.8 \pm 7.3$ & $64.1 \pm 6.8$ & $64.6 \pm 6.8$ \\
Disease duration & $6.5 \pm 5.3$ & $7.5 \pm 5.5$ & $22.3 \pm 4.2$ & $7.6 \pm 4.7$ \\
FEV1 \% pred & $60.9 \pm 9.0$ & $36.4 \pm 5.0$ & $51.5 \pm 14.2$ & $39.9 \pm 17.0$ \\
VC\% pred & $83.2 \pm 13.9$ & $64.7 \pm 14.4$ & $20.7 \pm 12.3$ & $66.6 \pm 18.9$ \\
TLCO \% pred & $47.1 \pm 25.6$ & $26.3 \pm 20.9$ & $207.4 \pm 83.4$ & $33.9 \pm 22.5$ \\
6MWD & $308.6 \pm 86.8$ & $47.5 \pm 93.1$ & $54.3 \pm 14.6$ & $260.7 \pm 95.7$ \\
SGRQ total & $36.4 \pm 19.1$ & $9.9 \pm 9.3$ & $46.0 \pm 18.3$ \\
SIP overall & $4.9 \pm 6.8$ & $3.1 \pm 0.5$ & $2.9 \pm 0.5$ & $8.5 \pm 8.1$ \\
MACL total & $3.1 \pm 0.8$ & & $3.0 \pm 0.6$ \\
\hline
\end{tabular}

Data are presented as mean \pm SD unless otherwise stated. M: males; F: females; VC: vital capacity; TLCO: carbon monoxide transfer factor; 6MWD: 6-min walking distance; SGRQ: St George's Respiratory Questionnaire; SIP: Sickness Impact Profile; MACL: Mood Adjective Check List; Disease duration: years since first occurrence of symptoms. 
marked dysfunction. The scores for the categories $\mathrm{A}, \mathrm{BCM}$ and $\mathrm{M}$ form a physical dimension (Phd) and the scores for the categories EB, SI, AB and C form a psychosocial dimension (Psd). All 12 categories are included in an overall SIP score (SIP overall).

Both the SIP and the SGRQ focus on physical dysfunction and should therefore be supplemented with generic measures of emotional distress and wellbeing.

Emotional distress. Hospital Anxiety and Depression Scale. A previously tested Swedish version [23] of the Hospital Anxiety and Depression Scale (HADS) [24] was used to assess emotional distress. The HADS was specifically developed for the detection of anxiety and depression in patients with somatic conditions. It consists of 14 items and gives separate scores for anxiety and depression. Higher scores indicate more emotional distress. Scores of $8-10$ indicate possible psychiatric morbidity and scores $>10$ probable psychiatric morbidity.

Emotional wellbeing. The Mood Adjective Check List. This is widely used in Sweden as a measure of emotional wellbeing [25]. A shortened 38-item version that has proven to have good validity and reliability [26] was used in the present study. It covers three basic dimensions of mood: pleasantness/ unpleasantness, activation/ deactivation and calmness/ tension. The scores for all the items form an overall Mood Adjective Check List (MACL) score. On this scale, higher scores indicate a more positive emotional state.

\section{Statistical methods}

Descriptive statistics were computed for each of the analysed variables. Two methods were used to identify the factors most associated with HRQL. 1) Parametric and nonparametric (Spearman) correlations were calculated to study the relationships between the HRQL measures and other variables. As no major discrepancies were found, Pearson correlation coefficients have been reported throughout. 2) Stepwise multiple regression [27] was used to identify the factors that were most strongly related to HRQL scores. All variables with a p-value of $<0.15$ were entered in the regression model, and all results with $p<0.05$ were accounted for. The following measures of HRQL were used as dependents: SIP overall score, SIP physical dimension, SIP psychosocial dimension, SGRQ total score and total MACL score. In order to avoid contamination, the following variables were excluded from the regression analyses: for the three SIP dimensions, the 12 separate SIP categories; for the SGRQ total score, the three separate SGRQ subscales; and for the MACL score, HADS anxiety and depression scores and SIP emotional behaviour. The analyses then followed the same hierarchical sequence of inclusion of independents. In the first regressions, only measures of lung function were included. Walking distance (6MWD) was then added, followed by the measures of emotional distress (HADS and
MACL scores), and finally the SIP and/or SGRQ categories. Thus, for each of the five dependents studied, four separate analyses were performed. Note that the specification of the various regression models as dependents and independents does not imply that the variables are conceptually related in a causal sense.

\section{Results}

Baseline characteristics are given in table 1. The patients were all former or current heavy smokers with a disease duration of several years. Of the patients, 21 had an FEV1 of $<30 \%$ pred, 25 had values $30-50 \%$ and 22 had values $50-80 \%$ pred. Seventeen patients $(25 \%)$ had chronic or intermittent respiratory insufficiency. Only 14 of the 37 patients below retirement age (65 yrs) were gainfully employed. Forty per cent of the patients were living alone and the remaining $60 \%$ cohabited with a partner.

The impact of the disease was considerable according to the SGRQ and slight to moderate according to the SIP. In the HADS, pathological levels (scores $>10)$ were seen in $13 \%$ of the subjects $(n=9)$ on the anxiety scale and $7 \%$ of the subjects $(n=5)$ on the depression scale.

Data 12 months later showed only small changes. Statistical significance $(\mathrm{p}<0.05)$ was found for: mean FEV1 \% pred, which decreased from 39.9 to $37.2 \%$ pred; mean vital capacity (VC), which decreased from 66.6 to $62.2 \%$ pred; and the mean of the SIP psychosocial scale score, which increased from 6.8 to 8.7 .

Pearson correlations for the overall SIP scores, the SGRQ total scores and FEV1 at baseline are given in table 2. The corresponding information on MACL scores is shown in figure 1. The SIP overall column in table 2 gives a sequence of correlations from low with lung function, to more substantial with overall MACL, HADS depression scores and 6MWD, to stronger with the SGRQ activity, impact and total scores. SGRQ total scores showed a similar sequence and magnitude of correlations. Here, too, the strongest correlations were to other HRQL measures, in this case the SIP physical categories (mobility, ambulation and home management) and the SIP sleep/rest category.

Of all the HRQL scales, SGRQ activity, the SIP ambulation and SIP home management scores correlated best with FEV1, $\mathrm{r}=0.49,0.49$ and 0.46 , respectively, ranking equal to or stronger than 6MWD. Of the lung function data, VC \% pred correlated best with the SIP overall scores and the SGRQ total scores; $r=0.50$ and 0.44 , respectively. In all series of correlations, 6MWD is located among the variables measuring self-rated functional status.

The FEV1 column illustrates an orderly sequence of correlations, starting with lung function, SGRQ activity, total and impacts scores, 6MWD, SIP physical and SIP psychosocial scores, and finally scores measuring emotional function. This sequence is almost completely reversed for the MACL scores (fig. 1), with lung function at one end and anxiety and 
Table 2. - Pearson correlations between Sickness Impact Profile (SIP) overall, St George's Respiratory Questionnaire (SGRQ) total scores, forced expiratory volume in one second (FEV 1 ) with other outcome measures

\begin{tabular}{|c|c|c|c|c|c|}
\hline \multicolumn{2}{|c|}{ SIP Overall } & \multicolumn{2}{|l|}{ SGRQ Total } & \multicolumn{2}{|l|}{ FEV1 } \\
\hline Outcome measure & Correlation & Outcome measure & Correlation & Outcome measure & Correlation \\
\hline $\mathrm{Pa}_{\mathrm{a}, \mathrm{O}_{2}}$ & NS & $\mathrm{Pa}, \mathrm{CO}_{2}$ & NS & HADS anxiety & NS \\
\hline $\mathrm{Pa}_{\mathrm{a}, \mathrm{CO}_{2}}$ & NS & SIP Work & NS & SIP emotional behaviour & NS \\
\hline HADS anxiety & $0.28 *$ & $P \mathrm{a}_{2} \mathrm{O}_{2}$ & NS & SIP work & NS \\
\hline SGRQ symptoms & $0.31 * *$ & SIP alertness behavior & $0.28 *$ & SIP alertness behaviour & NS \\
\hline FEV1 & $0.32 * *$ & SIP communication & $0.31 * *$ & HADS depression & NS \\
\hline TLCO & $0.35^{* *}$ & HADS anxiety & $0.36^{* *}$ & SGRQ symptoms & NS \\
\hline $\mathrm{VC}$ & $0.50 * * *$ & TLCO & $0.37 * *$ & MACL & NS \\
\hline MACL & $0.52 * * *$ & FEV1 & $0.42 * * *$ & SIP psychosocial dimension & NS \\
\hline HADS depression & $0.57 * * *$ & $\mathrm{VC}$ & $0.44 * * *$ & SIP sleep and rest & NS \\
\hline 6MWD & $0.62 * * *$ & SIP recreation/pastimes & $0.46^{* * *}$ & SIP body care/movement & NS \\
\hline SGRQ activity & $0.64 * * *$ & SIP emotional behavior & $0.49^{* * *}$ & SIP communication & NS \\
\hline SGRQ impacts & $0.69 * * *$ & SIP body care/movement & $0.49 * * *$ & SIP social interaction & NS \\
\hline \multirow[t]{15}{*}{ SGRQ total } & $0.69 * * *$ & SIP eating & $0.51 * * *$ & SIP mobility & $0.25^{*}$ \\
\hline & & SIP social interaction & $0.54 * * *$ & SIP overall & $0.32 * *$ \\
\hline & & MACL & $0.54 * * *$ & SIP physical dimension & $0.34 * *$ \\
\hline & & SIP psychosocial dimension & $0.56 * * *$ & $P \mathrm{a}, \mathrm{O}_{2}$ & $0.39 * *$ \\
\hline & & SIP home management & $0.58 * * *$ & SGRQ impacts & $0.40^{* * *}$ \\
\hline & & HAD depression & $0.59 * * *$ & SIP recreation/pastimes & $0.41 * * *$ \\
\hline & & SIP ambulation & $0.60 * * *$ & SGRQ total & $0.42 * * *$ \\
\hline & & 6MWD & $0.61^{* * *}$ & SIP eating & $0.42 * * *$ \\
\hline & & SIP mobility & $0.61 * * *$ & 6MWD & $0.45^{* * *}$ \\
\hline & & SIP sleep and rest & $0.62 * * *$ & SIP home management & $0.46^{* * *}$ \\
\hline & & SIP physical dimension & $0.64 * * *$ & SIP ambulation & $0.49 * * *$ \\
\hline & & SIP overall & $0.69 * * *$ & SGRQ activity & $0.49 * * *$ \\
\hline & & & & TLCO & $0.52 * * *$ \\
\hline & & & & $P \mathrm{a}, \mathrm{CO}_{2}$ & $0.56 * * *$ \\
\hline & & & & $\mathrm{VC}$ & $0.71 * * *$ \\
\hline
\end{tabular}

Intra-scale correlations are not presented. NS: nonsignificant; $\mathrm{Pa}, \mathrm{O}_{2}$ : oxygen tension in arterial blood; $\mathrm{Pa}_{\mathrm{a}} \mathrm{CO}_{2}$ : carbon dioxide tension arterial blood; HADS: Hospital Anxiety and Depression Scale; TLCO: carbon monoxide transfer factor; VC: vital capacity; MACL: Mood Adjective Check List; 6MWD: 6-min walking distance. *: $\mathrm{p}<0.05 ; * *: \mathrm{p}<0.01 ;{ }^{* * *}: \mathrm{p}<0.001$. No consideration has been taken to direction of correlations.

depression scores at the other. The correlation between FEV1 and the SGRQ and the SIP overall scores were -0.42 and -0.32 , respectively.

Little or no correlation was found between age, sex, domestic arrangements and the HRQL scores.

\section{Multiple regression analyses}

Overall SIP scores (table 3) showed that, with the SGRQ components included in the model, $67 \%$ of the overall SIP variance was explained, mainly by the SGRQ activity scores (partial $\mathrm{R}^{2}=0.50$ ). When SGRQ scores were excluded, depression scores (HADS) and 6MWD emerged as the best predictors. Lung function alone predicted $29 \%$ of the overall SIP scores.

SIP physical dimension (table 3) showed that SGRQ activity again explained most of the variance (partial $\mathrm{R}^{2}=0.44$ ), followed by 6MWD, depression scores and lung function. Regarding SIP psychosocial dimension (table 3) depression (HADS) was the best predictor (partial $\mathrm{R}^{2}=0.44$ ), followed by $6 \mathrm{MWD}$. Lung function alone only accounted for $6 \%$ of the variance.

The SGRQ total scores (table 4) showed that when the SIP categories were included, SIP sleep/rest and SIP home management showed the strongest relations, followed by depression (HADS) and 6MWD. Lung function alone accounted for $21 \%$ of the variance. Data for the SGRQ impacts scores were almost identical. The SGRQ activity scores correlated best with the SIP ambulation scores (partial $\mathrm{R}^{2}=0.48$ ), followed by $6 \mathrm{MWD}$, while MACL played a minor role. Lung function accounted for $27 \%$ of the variance. Only $22 \%$ of the variance in SGRQ symptoms scores was accounted for (SIP body care/ movement, partial $\mathrm{R}^{2}=0.05$; SIP emotional behaviour, 0.17). Data for the SGRQ section scores are not shown.

The MACL scores (table 5) showed that MACL was mainly associated with the SGRQ activity scores (partial $\mathrm{R}^{2}=0.32$ ). Lung function and 6MWD played a minor role. A separate analysis (not shown) with the HADS scores as independent variables showed HADS depression to predict $65.5 \%$ and HADS anxiety a further $6.2 \%$ of the variance in MACL scores (total $\mathrm{R}^{2}=71.7 \%$ ).

\section{Discussion}

A systematic investigation was conducted to identify factors related to HRQL in COPD patients. Three generic instruments covering basic dimensions of HRQL were supplemented with a disease-specific 


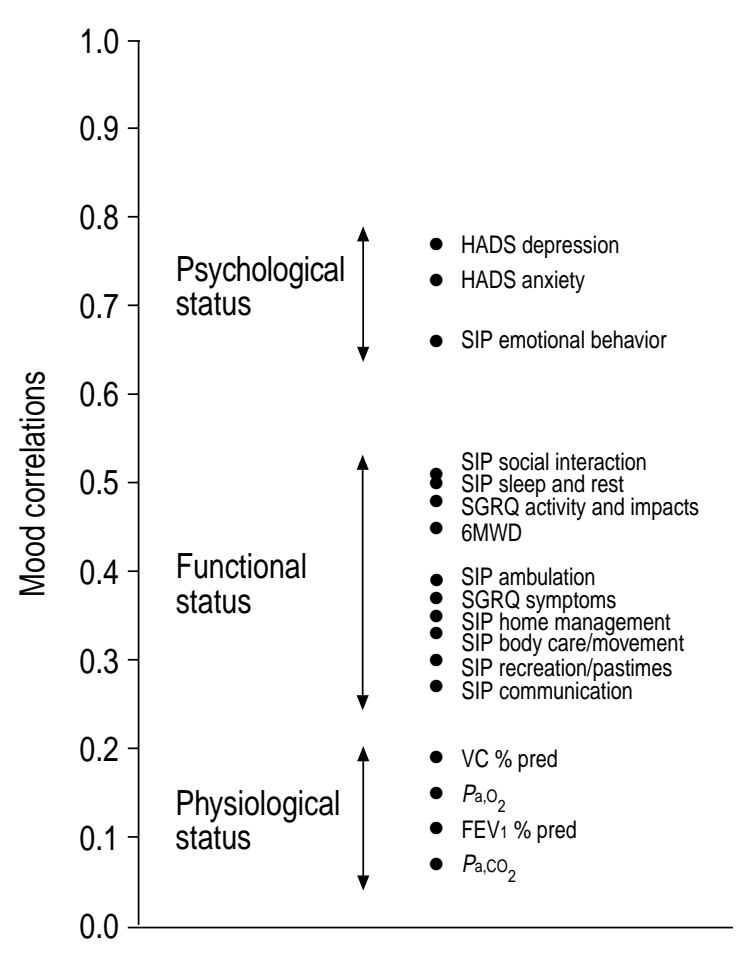

Fig. 1. - Pearson correlations between mood scores (Mood Adjective Check List (MACL)) and data representing physiological, functional and psychological status. HADS: Hospital Anxiety and Depression Scale; SIP: Sickness Impact Profile; SGRQ: St George's Respiratory Questionnaire; 6MWD: 6-min walking distance; $\mathrm{VC}$ : vital capacity; $\mathrm{Pa}, \mathrm{O}_{2}$ : oxygen tension in arterial blood; $\mathrm{Pa}_{\mathrm{a}} \mathrm{CO}_{2}$ : carbon dioxide tension in arterial blood; $\mathrm{FEV}_{1}$ : forced expiratory volume in one second.

measure and clinical indicators. Together, these measures examined the effects of COPD on lung function, symptoms, physical function, psychosocial function and emotional status. The presented results show that the measures within each of these groups are highly related internally, but only moderately to poorly between each other. However, an orderly sequence of relationships between these groups of measures can be outlined. Measures of lung function, showed moderate correlations with measures of physical function, small with measures of psychosocial function and nonsignificant correlations with measures of emotional status. This continuum is most evident in the correlation series for FEV1 (table 2) and for MACL (fig. 1). This model of relationships is of importance for guiding the choice of relevant HRQL instruments. For example, an intervention designed to increase FEV1 can be expected to have an impact on physical function, but less so for the dimensions further along the continuum. In the same manner, a successful psychological intervention should produce effects on the variables measuring emotional status and psychosocial function, but not on those more "distant" from this target. It can be concluded that a comprehensive assessment of the effects of COPD requires a battery of instruments that not only taps the disease-specific effects in lung function and symptoms, but also the overall burden of the disease on everyday functioning and emotional wellbeing.

In this study, a separate dyspnoea scale was not
Table 3.-Results of the stepwise multiple regression analyses with Sickness Impact Profile (SIP) overall score, SIP physical score and SIP psychosocial score as the dependent variables

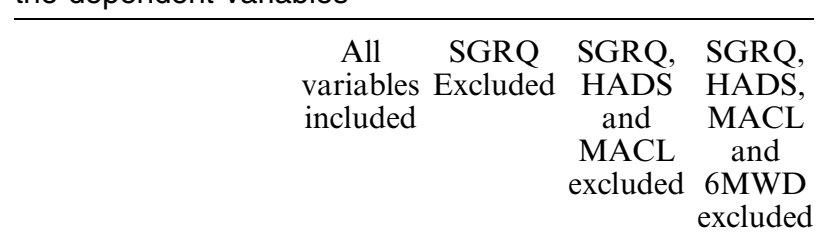

\begin{tabular}{|c|c|c|c|c|}
\hline \multicolumn{5}{|l|}{ SIP overall } \\
\hline SGRQ symptoms & \\
\hline SGRQ activity & \multicolumn{4}{|l|}{$0.50 * * *$} \\
\hline \multicolumn{5}{|l|}{ SGRQ impacts } \\
\hline \multicolumn{5}{|l|}{ HADS anxiety } \\
\hline \multicolumn{5}{|l|}{ MACL } \\
\hline 6MWD & & $0.05 *$ & $0.34 * * *$ & \\
\hline VC $\%$ pred & $0.04 *$ & $0.15 * * *$ & $0.04 *$ & $0.20 * * *$ \\
\hline FEV $1 \%$ pred & $0.04 *$ & & & $0.05^{*}$ \\
\hline TLCO \% pred & & & & $0.04 *$ \\
\hline Total $\mathrm{R}^{2}$ & 0.67 & 0.59 & 0.38 & 0.29 \\
\hline \multicolumn{5}{|l|}{ SIP physical } \\
\hline \multicolumn{5}{|l|}{ SGRQ symptoms } \\
\hline SGRQ activity & $0.44 * * *$ & & & \\
\hline \multicolumn{5}{|l|}{ SGRQ impacts } \\
\hline \multicolumn{5}{|l|}{ HADS anxiety } \\
\hline HADS depression & $0.05^{*}$ & $0.11 * * *$ & & \\
\hline 6MWD & $0.10^{* *}$ & $0.42 * * *$ & $0.42 * * *$ & \\
\hline VC $\%$ pred & $0.04 *$ & $0.07 * *$ & $0.05^{*}$ & $0.24 * * *$ \\
\hline FEV1 $\%$ pred & $0.03^{*}$ & & & \\
\hline TLCO \% pred & & & & \\
\hline Total $\mathrm{R}^{2}$ & 0.66 & 0.60 & 0.47 & 0.24 \\
\hline \multicolumn{5}{|l|}{ SIP psychosocial } \\
\hline \multicolumn{5}{|l|}{ SGRQ symptoms } \\
\hline SGRQ activity & $0.06^{*}$ & & & \\
\hline \multicolumn{5}{|l|}{ SGRQ impacts } \\
\hline \multicolumn{5}{|l|}{ HADS anxiety } \\
\hline HADS depression & $0.44 * * *$ & $0.44 * * *$ & & \\
\hline MACL & & $0.04 *$ & & \\
\hline 6MWD & & $0.05^{*}$ & $0.22 * * *$ & \\
\hline VC $\%$ pred & $0.03 *$ & & & $0.06^{*}$ \\
\hline FEV1 \% pred & & & & \\
\hline $\begin{array}{l}\text { TLCO \% pred } \\
\text { Total } \mathrm{R}^{2}\end{array}$ & 0.53 & 0.53 & 0.22 & 0.06 \\
\hline
\end{tabular}

SGRQ: St George's Respiratory Questionnaire; HADS: Hospital Anxiety and Depression Scale; MACL: Mood Adjective Check List; 6MWD: 6-min walking distance; VC: vital capacity; FEV1: forced expiratory volume in one second; TLCO: carbon monoxide transfer factor. Only significant estimates $\left(\mathrm{R}^{2}\right)$ are shown $(\mathrm{p}<0.05)$. ${ }^{*}: \mathrm{p}<0.05$. $* *: p<0.01$. ***: $p<0.001$.

used since the activity section of the SGRQ has been shown to be closely associated with dyspnoea scales [28]. The associations found between HRQL and age, sex and marital status were nonsignificant and/or small, and did not confound the main results of this work.

The presented results show, as expected, that overall SIP scores relate most strongly to other SIP scores, the SGRQ total scores to other SGRQ scores, the MACL scores to other psychological scores, and FEV1 to other lung function data. The SIP work limitations category is an exception in having no 
Table 4.-Results of the stepwise multiple regression analyses with the St George's Respiratory Questionnaire (SGRQ) total score as the dependent variable

\begin{tabular}{|c|c|c|c|c|}
\hline & $\begin{array}{l}\text { All variables } \\
\text { included }\end{array}$ & $\begin{array}{l}\text { SIP categories } \\
\text { excluded }\end{array}$ & $\begin{array}{l}\text { SIP categories, HADS } \\
\text { and MACL excluded }\end{array}$ & $\begin{array}{l}\text { SIP categories, HADS, } \\
\text { MACL and 6MWD excluded }\end{array}$ \\
\hline \multicolumn{5}{|l|}{ SGRQ Total score } \\
\hline \multicolumn{5}{|l|}{ SIP ambulation } \\
\hline \multicolumn{5}{|c|}{ SIP body care and movement } \\
\hline \multicolumn{5}{|l|}{ SIP mobility } \\
\hline \multicolumn{5}{|l|}{ SIP emotional behaviour } \\
\hline \multicolumn{5}{|l|}{ SIP social interaction } \\
\hline \multicolumn{5}{|l|}{ SIP alertness behaviour } \\
\hline \multicolumn{5}{|l|}{ SIP communication } \\
\hline \multicolumn{5}{|l|}{ SIP work } \\
\hline SIP sleep and rest & $0.44 * * *$ & & & \\
\hline \multicolumn{5}{|l|}{ SIP eating } \\
\hline \multirow{2}{*}{\multicolumn{5}{|c|}{$\begin{array}{l}\text { SIP home management } \\
\text { SIP recreation and pastimes }\end{array}$}} \\
\hline & & & & \\
\hline \multicolumn{5}{|l|}{ HADS anxiety } \\
\hline \multirow{2}{*}{\multicolumn{5}{|c|}{ MACL }} \\
\hline & & & & \\
\hline 6MWD & & & $0.33^{* * *}$ & \\
\hline VC $\%$ pred & & $0.14 * * *$ & & $0.14^{* *}$ \\
\hline FEV $1 \%$ pred & $0.03 *$ & & & \\
\hline TLCO $\%$ pred & & $0.05 *$ & & $0.07 *$ \\
\hline Total $\mathrm{R}^{2}$ & 0.69 & 0.58 & 0.33 & 0.21 \\
\hline
\end{tabular}

SIP: Sickness Impact Profile; HADS: Hospital Anxiety and Depression Scale; MACL: Mood Adjective Check List; 6MWD: 6-min walking distance; VC: vital capacity; FEV1: forced expiratory volume in one second; TLCO: carbon monoxide transfer factor. Only significant estimates $\left(\mathrm{R}^{2}\right)$ are shown $(\mathrm{p}<0.05)$. ${ }^{*}: \mathrm{p}<0.05 . * *: \mathrm{p}<0.01$. $* * *: \mathrm{p}<0.001$.

correlations to any of the other variables. This is probably due to the relatively small number of patients in working age, as well as to the peculiarities in the scoring algorithm for this category.

There is a strong correlation between the overall SIP and SGRQ total scores, and also between most of their respective subscores. This was also expected since both measures (except SGRQ symptoms) are intended to measure functional aspects of HRQL. In contrast, SGRQ symptoms scores had, at most, only modest correlations with the overall SIP and MACL scores, and no association was found with FEV1. This

Table 5. - Results of the stepwise multiple regression analyses with the Mood Adjective Check List (MACL) score as the dependent variable

\begin{tabular}{|c|c|c|c|c|}
\hline & $\begin{array}{l}\text { All variables } \\
\text { included }\end{array}$ & $\begin{array}{l}\text { SIP categories } \\
\text { excluded }\end{array}$ & $\begin{array}{l}\text { SIP categories, and } \\
\text { SGRQ excluded }\end{array}$ & $\begin{array}{l}\text { SIP categories, SGRQ } \\
\text { and } 6 \mathrm{MWD} \text { excluded }\end{array}$ \\
\hline \multicolumn{5}{|l|}{ MACL scores } \\
\hline \multicolumn{5}{|l|}{ SIP ambulation } \\
\hline \multicolumn{5}{|c|}{ SIP body care and movement } \\
\hline \multicolumn{5}{|c|}{ SIP mobility } \\
\hline \multicolumn{5}{|c|}{ SIP social interaction } \\
\hline \multicolumn{5}{|c|}{ SIP alertness behaviour } \\
\hline \multicolumn{5}{|c|}{ SIP communication } \\
\hline \multicolumn{5}{|c|}{ SIP work } \\
\hline \multicolumn{5}{|c|}{ SIP sleep and rest } \\
\hline \multicolumn{5}{|c|}{ SIP eating } \\
\hline \multicolumn{5}{|c|}{ SIP home management } \\
\hline \multicolumn{5}{|c|}{ SIP recreation and pastimes } \\
\hline \multicolumn{5}{|c|}{ SGRQ symptoms } \\
\hline SGRQ activity & $0.32 * * *$ & $0.32 * * *$ & & \\
\hline \multicolumn{5}{|l|}{ SGRQ impacts } \\
\hline \multirow{2}{*}{\multicolumn{5}{|c|}{ 6MWD }} \\
\hline & & & & \\
\hline \multirow{2}{*}{\multicolumn{5}{|c|}{ FEV $1 \%$ pred }} \\
\hline TLCO \% pred & & & & \\
\hline Total $\mathrm{R}^{2}$ & 0.40 & 0.40 & 0.12 & NS \\
\hline
\end{tabular}

SIP: Sickness Impact Profile; SGRQ: St George's Respiratory Questionnaire; 6MWD: 6-min walking distance; VC: vital capacity; FEV1: forced expiratory volume in one second; TLCO: carbon monoxide transfer factor; NS: nonsignificant. Only significant estimates $\left(\mathrm{R}^{2}\right)$ are shown $(\mathrm{p}<0.05)$. **: $\mathrm{p}<0.01 ; * *: \mathrm{p}<0.001$. 
is in accordance with the conceptual model of HRQL, where symptoms are distinctly separate from function and wellbeing. It must also be noted that 6MWD was located close to the self-reported data on physical function, correlating most strongly with the SGRQ activity and the SIP physical dimension scores $(\mathrm{r}=-0.63$ and -0.67 , respectively). Moreover, 6MWD is the only clinical measurement related to MACL. Thus, 6MWD appears to represent a more multidetermined measure in which physiological, physical and emotional aspects are involved, and consequently, complements other kinds of exercise tests and HRQL measures.

Stronger relationships were found between lung function and SIP and SGRQ scores than most other investigators $[1-4,9-14]$. This is probably due to differing characteristics of the study populations. The population used in the present study consisted of patients with a very wide FEV1 \% pred $(12-79 \%)$, while in other studies the spectrum of FEV1 has been smaller, possibly masking the effects of pulmonary function on HRQL. It was found that FEV1 related best to the SGRQ activity section $(r=0.49)$ and the SIP ambulation category $(\mathrm{r}=0.49)$, while VC related best to the SIP physical dimension $(r=0.52)$. VC also correlated better with overall SIP scores than FEV1. The reason for this is unclear, however, this finding has also been reported by JoNEs et al. [3].

The regression analyses showed that although pulmonary function is important, its relation to health-related quality of life is significantly modulated by three of the factors examined in the present study: 6-min walking distance, dyspnoea-related limitation and depression scores (Hospital Anxiety and Depression Scale). The logical approach must be to study the factors that are in turn associated with these main factors. This has been done to some extent, but not systematically. Dyspnoea intensity as measured by the visual analogue or Borg scales, especially the relationships of visual analogue or Borg scales to work load or minute ventilation, has been thoroughly investigated in previous studies. For example, pulmonary hyperinflation has been described as an important predictor [29]. The dyspnoea threshold scales, which are conceptually closer to functional status, have been studied to a lesser degree. As a rule, only modest correlations to lung function have been found [28]. The finding that body composition influences healthrelated quality of life as measured by the St George's Respiratory Questionnaire via dyspnoea is a further step [14]. Factors behind 6-min walking distance have not been systematically investigated, but two aspects have been described: body composition and psychological factors [30, 31]. Finally, the Hospital Anxiety and Depression Scale depression scores were related to most aspects of health-related quality of life. This was especially true for the emotional wellbeing or Mood Adjective Check List. In the present study, patients with chronic obstructive pulmonary disease had slightly lower Mood Adjective Check List scores compared to healthy controls [5]. However, among the patients, lung function did not correlate with Mood Adjective Check List scores. This means that when the disease is established, other factors tend to predominate. Therefore, factors behind low mood and/or depression in chronic obstructive pulmonary disease should be further investigated. One study [12] has described a coping factor, namely emotional reaction (to disease), as one determinant of mood status. In addition, another aspect, fatigue, measured by the Sickness Impact Profile sleep/rest category appears to be related with the St George's Respiratory Questionnaire and Mood Adjective Check List scores. This corroborates the findings of two other studies $[15,17]$.

\footnotetext{
Acknowledgements. The authors gratefully acknowledge the assistance of A-M. Hilmersson, clinical research nurse, in monitoring the study.
}

\section{References}

1. McSweeny AJ, Grant I, Heaton RK, Adams KM, Timms RM. Life quality of patients with chronic obstructive pulmonary disease. Arch Intern Med 1982; 142: $473-478$.

2. Prigatano GP, Wright EC, Levin D. Quality of life and its predictors in patients with mild hypoxemia and chronic obstructive pulmonary disease. Arch Intern Med 1984; 144: 1613-1619.

3. Jones PW, Baveystock CM, Littlejohns P. Relationships between general health measured with the Sickness Impact Profile and respiratory symptoms, physiological measures and mood in patients with chronic airflow limitation. Am Rev Respir Dis 1989; 140: $1538-1543$.

4. Schrier AC, Dekker FW, Kaptein AA, Dijkman JH. Quality of life in elderly patients with chronic nonspecific lung disease seen in family practice. Chest 1990; 98: 894-899.

5. Engström CP, Persson LO, Larsson S, Rydén A, Sullivan M. Functional status and well being in chronic obstructive pulmonary disease with regard to clinical parameters and smoking: a descriptive and comparative study. Thorax 1996; 51: 825-830.

6. Curtis JR, Deyo RA, Hudson LD. Health-related quality of life among patients with chronic obstructive pulmonary disease. Thorax 1994; 49: $162-170$.

7. Leidy NK. Functional performance in people with chronic obstructive pulmonary disease. Image $J$ Nurs Sch 1995; 27: 23-24.

8. Bergner M, Bobbit RA, Carter WB, Gilson BS. The Sickness Impact Profile: development and final revision of a health status measure. Med Care 1981; 19: $787-805$.

9. Williams SJ, Bury MR. Impairment, disability and handicap in chronic respiratory illness. Soc Sci Med 1989; 29: 609-616.

10. Graydon JE, Ross E. Influence of symptoms, lung function, mood, and social support on level of functioning of patients with COPD. Res Nurs Health 1995; 18: 525-533.

11. Jones PW, Quirk FH, Baveystock CM, Littlejohns P. A self-complete measure of health status for chronic airflow limitation. The St. George's Respiratory Questionnaire. Am Rev Respir Dis 1992; 145: $1321-$ 1327. 
12. Ketelaars CAJ, Schlösser MAG, Mostert R, Huyer Abu-Saad H, Halfens RJG, Wouters EFM. Determinants of health-related quality of life in patients with chronic obstructive pulmonary disease. Thorax 1996; 51: $39-43$.

13. Hajiro $T$, Nishimura $K$, Tsukino $M$, Ikeda $A$, Koyama H, Izumi T. Comparison of discriminative properties among disease-specific questionnaires for measuring health-related quality of life in patients with chronic obstructive pulmonary disease. Am J Respir Crit Care Med 1998; 157: 785-790.

14. Shoup R, Dalsky G, Warner S, et al. Body composition and health-related quality of life in patients with obstructive airways disease. Eur Respir J 1997; 10: $1576-1580$.

15. Breslin E, van der Schans C, Breukink S, et al. Perception of fatigue and quality of life in patients with COPD. Chest 1998; 114: 958 -964.

16. Okubadejo AA, Jones PW, Wedzicha JA. Quality of life in patients with chronic obstructive pulmonary disease and severe hypoxaemia. Thorax 1996; 51: 4447.

17. Small SP, Graydon JE. Perceived uncertainty, physical symptoms and negative mood in hospitalized patients with COPD. Heart Lung 1992; 21: 568 - 574.

18. Berglund E, Birath G, Bjure J, et al. Spirometric studies in normal subjects. I. Forced expirograms in subjects between 7 to 70 years of age. Acta Med Scand 1963; 173: 185-191.

19. Salorinne Y. Single-breath pulmonary diffusing capacity. Reference values and application in connective tissue diseases and in various lung diseases. Scand J Respir Dis: 1976: Suppl. 96, 12-16.

20. Butland RJA, Pang J, Gross ER, Woodcock AA, Geddes D. Two-, six- and 12-minute walking tests in respiratory disease. BMJ 1982; 284: $1607-1608$.

21. Engström CP, Persson LO, Larsson S, Sullivan M. Reliability and validity of a Swedish version of the St
George's Respiratory Questionnaire. Eur Respir J 1998; 11: 61-66.

22. Sullivan M, Ahlmén M, Archenholtz B, Svensson G. Measuring health in rheumatic disorders by means of a Swedish version of the Sickness Impact Profile: results from a population study. Scand J Rheumatol 1986; 15: $193-200$.

23. Sullivan M, Karlsson J, Sjöström L, Backman L, Bengtsson C, Bouchard C. Swedish obese subjects (SOS) - an intervention study of obesity. Baseline evaluation of health and psychological functioning in the first 1743 subjects examined. Int $J$ Obes Relat Metab Disord 1993; 17: 503-512.

24. Zigmund AS, Snaith RP. The hospital anxiety and depression scale. Acta Psychiatr Scand 1983; 286: $171-173$.

25. Sjöberg L, Svensson E, Persson LO. The measurement of mood. Scand J Psychol 1979; 20: 1-18.

26. Lundqvist C, Sjösteen A, Blomstrand C, Lind B, Sullivan M. Spinal cord injuries. Clinical, functional and emotional status. Spine 1991; 16: $78-83$.

27. Draper NR, Smith H. Applied Regression Analysis. New York, John Wiley and Sons, Inc., 1966.

28. Hajiro $T$, Nishimura $K$, Tsukino $M$, Ikeda $A$, Koyama H, Izumi T. Analysis of clinical methods used to evaluate dyspnea in patients with chronic obstructive pulmonary disease. Am J Respir Crit Care Med 1998; 158: 1185-1189.

29. O'Donnel DE, Webb K. Exertional breathlessness in patients with CAL: the role of lung hyperinflation. $\mathrm{Am}$ Rev Respir Dis 1993; 48: $1351-1357$.

30. Schols AMWJ, Mostert R, Soeters PB, Wouters EFM. Body composition and exercise performance in patients with chronic obstructive pulmonary disease. Thorax 1991; 46: 695-699.

31. King B, Cotes JE. Relation of lung function and exercise capacity to mood and attitudes to health. Thorax 1989; 44: 402-409. 